\title{
SO IIMAIRE
}

Comité jnternational. -- Ia guerro serbu-bulgare, 5. - Appel en faveur

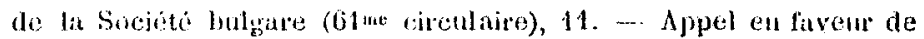
la sincitie serbs (6\%ue circulatro), 1\%. ..... Mode de transmission des

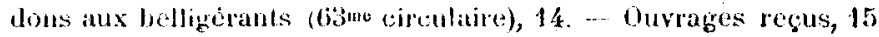

Allemagne. -- Comespondance de Berlin, 16. -- Les pransenents antiseptiques dans latmée allemande, 20.

Autriche -. La guere serbo-bulgare, 21. - Le journal " La CroixRuuge, 28.

Baviòre. --. Lat Societr bavaroise pendant les andées 1880 à $1884,31$.

Bulgarie. - Statuts de la Sociéle bulgare de la Croix-Ronge, 34.

Danemark: -. La batajue d'atubulance do MM. Christoph et Unmack, par M. Aitrien Peyrot, 38.

Etats-Unis. -- Bilsliographie rocidiate, 44.

France. - Nouvelles de la Société francaise, 45.

Grande-13retagno, - .. La Caoix-liouge en Angleterre, 49.

Italis - Emprunt a lots, 57.

Pays-Bas. - Instraction des infirnicrs et des intrmiònes volontaires, 57.

Russie. - La communauté des scurrs de St-Georere, 63.

Saxe. - La Sucićté Albort en 188\%, 65.

Serbie -... La sucicte serbe en 1881-8:3, 6i.

Suisse. - La Sovidé des Santaritains i berue, par M. Ernest Mockix, 70.

Le Bulletin international parait régulièrement tous les trois mois. Prix, franco, pour un an et pour tous les pays de l'Union postale, ( lro zonc), six fialles.

On s'abonne auprès du Comité international ọ des divers Comités centraux (voir leurs adresses ci-coulde). 